\title{
Unusual Urethral Metastasis from Colon Carcinoma Presenting with Difficult Urination and Hematuria
}

\author{
Ayhan Karakose Ozgu Aydogdu Yusuf Z. Atesci \\ Izmir University School of Medicine, Department of Urology, Karsiyaka, Izmir, Turkey
}

\section{Key Words}

Hematuria • Metastatic colonic adenocarcinoma •

Adenocarcinoma $\cdot$ Bulbar urethra

\begin{abstract}
Urethral metastases originating from the colon are extremely rare. We report a case of a 67-year-old man who presented with difficult urination and hematuria. Diagnostic cystoscopy showed an abnormal, exophytic lesion in his proximal penile urethra a bulbar urethra. His pathology was diagnosed as adenocarcinoma consistent with colon metastasis.
\end{abstract}

Copyright $\odot 2013$ S. Karger AG, Basel

\section{Introduction}

Primary urethral tumors are rare. Urethral metastases are even rarer. Urethral metastasis is less than $0.02 \%$ to all urological cancers [1]. Urethral metastases have been document as originating from the colon, lungs, kidneys, and prostate $[2,3]$.

Urethral metastases originating from the colon are extremely rare, and to the best of our knowledge this is the twelfth case reported in the medical literature [3-6].

\section{Case Report}

A 67-year-old man admitted to the outpatient urology clinic with difficult urination and hematuria for a week. His medical history had an open sigmoid colectomy and loop ileostomy 2 years ago. Pathological diagnosis was pT3 adenocarcinoma of the sigmoid colon. Postoperatively he had received adjuvant chemotherapy. He had undergone reversal of his loop ileostomy following completion of the chemotherapy. He was followed-up with an annual colonoscopy, CT of the thorax, abdomen and pelvis and measurement of CEA and CA-125 tumor markers by colorectal and oncology teams. All of the investigations were within normal limits and there was no evidence of disease recurrence or metastasis when last evaluated in January 2013. However, the patient presented to the outpatient urology clinic 5 months later complaining of difficult urination and hematuria. Diagnostic cystoscopy showed an abnormal, exophytic lesion in his proximal penile urethra a bulbar urethra (fig. 1). A lesion occluding in the lumen of the urethra was seen but a flexible cystoscope was passed to the lumen of the urethra. There was no tumor in the bladder. The lesions at penile and bulbar urethra were resected (fig. 2). Pathology diagnosed adenocarcinoma consistent with colon metastasis. A CT scan revealed liver metastasis. A PET scan also showed a 'hot spot' at his penile and bulbar urethra. The patient was given detailed information about probable complications such as urethral stricture, recurrence, and treatment failure. No complications occurred during or after the operation. The patient was discharged without any complications at postoperative day 1 . The patient is receiving chemotherapy for cancer control and his urine flow rate is good. He is being followed-up by colorectal, urology and oncology teams.

\section{KARGER}

Fax +4161306 1234

E-Mail karger@karger.ch

www.karger.com
(C) 2013 S. Karger AG, Base

1015-9770/13/0073-0152\$38.00/0

Accessible online at:

www.karger.com/cur
Ayhan Karakose

Izmir University School of Medicine, Department of Urology

TR-35510 Izmir (Turkey)

E-Mail drayhankarakose@gmail.com 

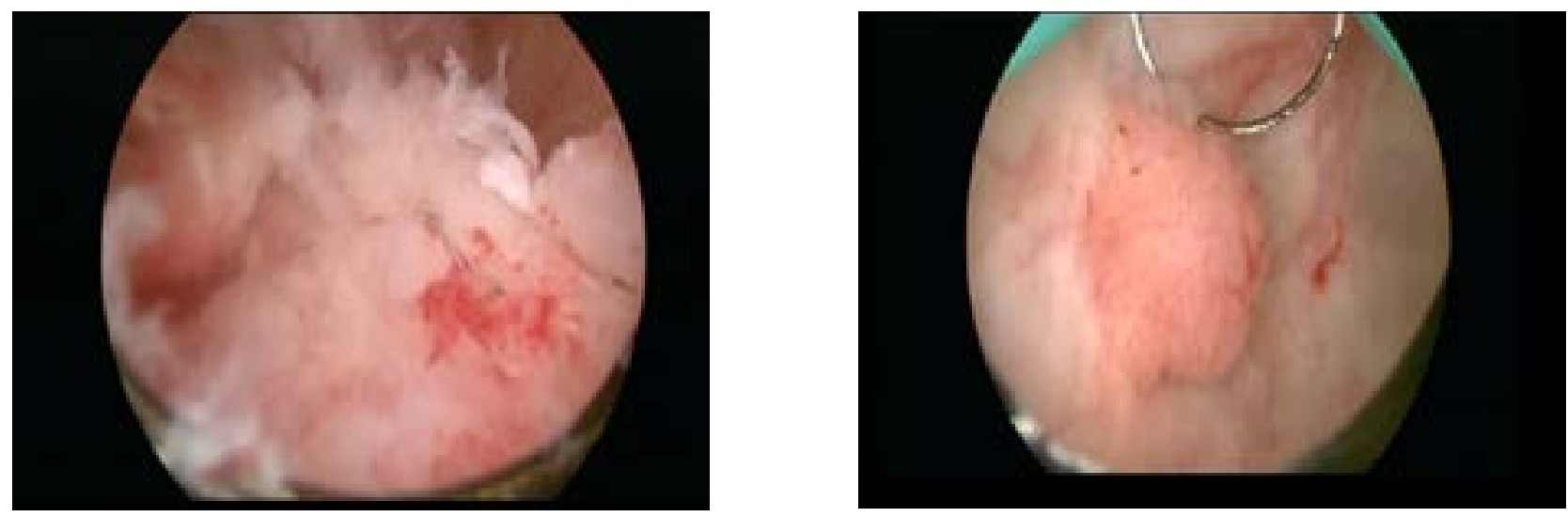

Fig. 1. Cystoscopic appearance of urethral metastasis.
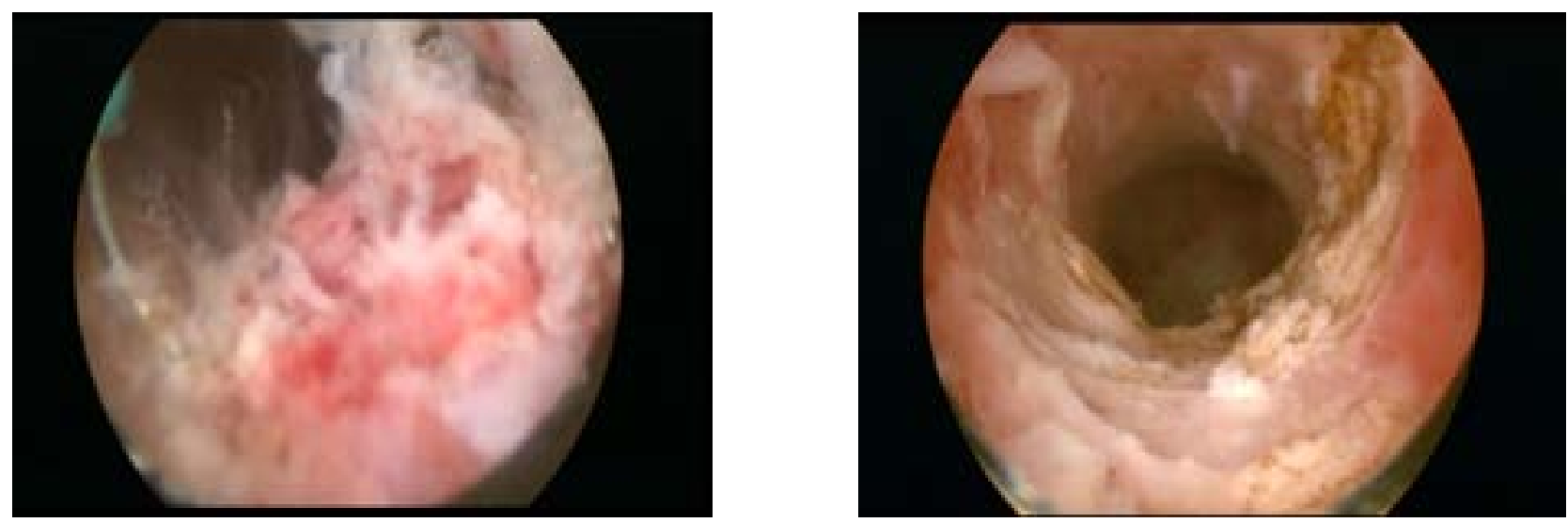

Fig. 2. Cystoscopic appearance after the resection of lesions in the urethra.

\section{Discussion}

Primary urethral tumors are rare. Squamous cell carcinoma is seen in $70 \%$ of tumors of the urethra. Adenocarcinoma is seen in $10-20 \%$ of tumors of the urethra. Urethral metastases have been reported as originating from the colon, kidneys, prostate and lungs [1-3].

Urethral metastases originating from the colon are extremely rare, and to the best of our knowledge this is the twelfth case reported in the medical literature [3-6]. The time from primary tumor metastatic lesion is $0.5-5$ years. The bulbar urethra is the most affected part of the urethra [1].

Unusual Urethral Metastasis from a Colon Carcinoma
Many hypotheses have described the mechanism of metastasis. Some of these are direct infiltration, lymphatic or hematogenous dissemination, and seeding of cancer cells through the urine. Some authors have suggested that pelvic recurrence may occur due to changes in lymphatic flow with pelvic surgery [4]. Yoshimura et al. [7] reported colon cancer cells directly planted into the urethra through the urine.

Most symptoms in men with urethral metastasis are urethral bleeding, hematuria and less acute urinary retention. Patients sometimes have penile masses or perineal masses. Cystoscopy must be performed to rule out urethral tumor if someone has these symptoms. MRI can be used to determine local extension [8]. 
Urethral metastasis from a colonic origin has a very poor prognosis [5]. Treatment of urethral metastasis from a colonic source must be undertaken via a multi-disciplinary approach. Local surgical excision is the treatment option for a solitary urethral lesion [4].

Urethral excision was performed in our case. Chemotherapy and radiotherapy was planned for our patient with liver metastases. There is no evidence that there is a survival advantage from urethral resection, but resection of the urethral lesion is effective in preventing lower urinary tract symptoms. However, it has a high relapse rate when surgery alone is used. Dalbangi et al. [9] advocated that chemotherapy, radiotherapy and surgery should be used together to control cancer and prevent distant metastasis. However, these treatment options do not provide good control of the cancer and new and more effective treatments should be explored.

\section{Conclusion}

Urethral metastasis arising from colorectal cancer is rare. Treatment must be a multidisciplinary and individualized approach. Surgery is the treatment options but surgical decisions should be made based on each patient's symptoms and the findings.

\section{References}

-1 Fukata S, Inoue K, Moriki T, Shuin T: A solitary metastasis of renal cell carcinoma to the urethra. J Urol 2000;163:1245-1246.

-2 Chitale SV, Burgess NA, Sethia KK, Love K, Roberts PF: Management of urethral metastasis from colorectal carcinomas. ANZ J Surg 2004;74:925-927.

>3 Noorani S, Rao AR, Callaghan PS: Urethral metastasis: an uncommon presentation of a colonic adenocarcinoma. Int Urol Nephrol 2007;39:837-839.

4 Okaneya T, Inoue y, Ogawa A: Solitary urethral recurrence of sigmoid colon carcinoma. Urol Int 1991;47:105-107.
75 Kupfer HW, Theunissen P, Delaere KP: Urethral metastasis from a rectal carcinoma. Acta Urol Belg 1995;63:31-32.

$>6$ Selikowitz SM, Olsson CA: Metastatic urethral obstruction. Arch Surg 1973;107:906908.

$>7$ Yoshimura K, Isogawa $\mathrm{Y}$, Yoshida $\mathrm{H}$, Kawase N, Taki Y: Recurrence of sigmoid colon carcinoma in the residual urethra after cystectomy. Int J Urol 1999;6:479-482.
8 Chang YH, Chuang CK, Ng KF, Liao SK: Urethral metastasis from a colon carcinoma. Urology 2007;69:575.e1-3.

9 Dalbagni G, Zhang ZF, Lacombe L, Herr HW: Male urethral carcinoma: analysis of treatment outcome. Urology 1999;53:11261132 . 